\title{
Review Article \\ Role of Vitamin D in Osteoarthritis: Molecular, Cellular, and Clinical Perspectives
}

\author{
Thomas Mabey $^{1}$ and Sittisak Honsawek ${ }^{1,2}$ \\ ${ }^{1}$ Department of Biochemistry, Faculty of Medicine, Chulalongkorn University, King Chulalongkorn Memorial Hospital, \\ Thai Red Cross Society, Bangkok 10330, Thailand \\ ${ }^{2}$ Department of Orthopaedics, Faculty of Medicine, Chulalongkorn University, King Chulalongkorn Memorial Hospital, \\ Thai Red Cross Society, Bangkok 10330, Thailand
}

Correspondence should be addressed to Sittisak Honsawek; sittisak.h@chula.ac.th

Received 2 December 2014; Revised 28 May 2015; Accepted 9 June 2015

Academic Editor: Kazuhiro Shiizaki

Copyright (C) 2015 T. Mabey and S. Honsawek. This is an open access article distributed under the Creative Commons Attribution License, which permits unrestricted use, distribution, and reproduction in any medium, provided the original work is properly cited.

\begin{abstract}
Osteoarthritis is a debilitating and degenerative disease which affects millions of people worldwide. The causes and mechanisms of osteoarthritis remain to be fully understood. Vitamin D has been hypothesised to play essential roles in a number of diseases including osteoarthritis. Many cell types within osteoarthritic joints appear to experience negative effects often at increased sensitivity to vitamin $\mathrm{D}$. These findings contrast clinical research which has identified vitamin $\mathrm{D}$ deficiency to have a worryingly high prevalence among osteoarthritis patients. Randomised-controlled trial is considered to be the most rigorous way of determining the effects of vitamin D supplementation on the development of osteoarthritis. Studies into the effects of low vitamin D levels on pain and joint function have to date yielded controversial results. Due to the apparent conflicting effects of vitamin D in knee osteoarthritis, further research is required to fully elucidate its role in the development and progression of the disease as well as assess the efficacy and safety of vitamin D supplementation as a therapeutic strategy.
\end{abstract}

\section{Introduction}

Osteoarthritis (OA) is a progressive and degenerative joint disease. Commonly affecting weight bearing synovial joints, $\mathrm{OA}$ is characterised by the degradation and loss of articular cartilage, abnormal subchondral bone growth and remodeling, and, in early stages, inflammation of the synovium. The complexity of OA has hindered attempts to understand its aetiology which still remains elusive. There are, however, a range of risk factors known to associate with OA including age, gender, obesity, previous joint trauma, and genetics [1]. Historically, it was assumed that only cartilage contributed to the progression of $\mathrm{OA}$, but all tissues within the joint structure are now known to be involved. In osteoarthritic knees, the most common location of OA, the subchondral tibial and femoral bones play central roles in the pathology of joint degeneration. Subchondral bone sclerosis, joint space narrowing, osteophyte formation, and loss of bone contours are evaluated using the Kellgren-Lawrence grading system for assessment of osteoarthritis [2] and reflect the severity of joint changes via radiography.

Vitamin D is a steroidal hormone that has many diverse biological actions in a number of target tissues. The primary functions of vitamin $\mathrm{D}$ are calcium homeostasis and regulation of bone metabolism; however, the full extent of vitamin D's biological action remains to be determined with a wide range of effects on different cell and tissue types being reported. Acting via the vitamin $\mathrm{D}$ receptor (VDR), vitamin $\mathrm{D}$ regulates circulating calcium and phosphate homeostasis through altering kidney reabsorption and intestinal absorption [3]. Parathyroid hormone (PTH) and fibroblast growth factor- (FGF-) 23, a bone-derived phosphaturic hormone produced in the presence of active vitamin D [4], are also major players involved in the maintenance of these circulating ion levels. PTH is secreted by the parathyroid glands in response to low calcium levels and acts to stimulate active vitamin $\mathrm{D}$ synthesis. This is achieved by inducing the release of calcium into the circulation via increased bone turnover 


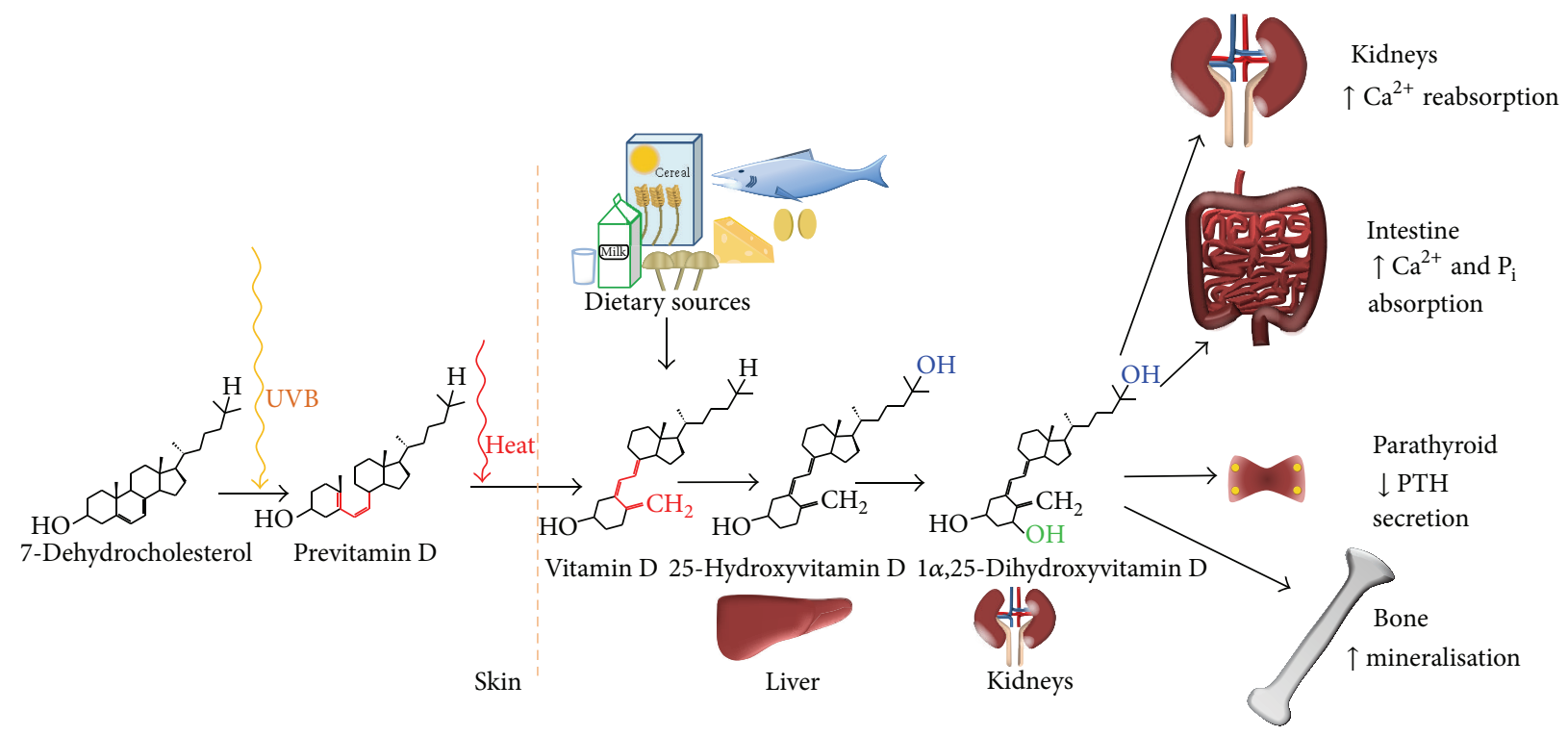

Figure 1: The biosynthesis of vitamin $\mathrm{D}$ and the major effects $1 \alpha, 25(\mathrm{OH})_{2} \mathrm{D}_{3}$ has on different organs. Synthesis begins in the skin before activation in the liver and kidneys. PTH: parathyroid hormone, Ca: calcium, and $\mathrm{P}_{\mathrm{i}}$ : inorganic phosphate.

to prevent hypocalcaemia [5]. With such a potent effect on bone, vitamin $\mathrm{D}$ has been investigated as to its role in OA. To date, numerous studies have shown its involvement and association with many aspects of the disease. Here we aim to review the current understanding of vitamin $\mathrm{D}$ and the roles it plays in osteoarthritis.

\section{Vitamin D Forms and Biosynthesis}

Vitamin $\mathrm{D}$ has two main forms, $\mathrm{D}_{2}$ and $\mathrm{D}_{3}$. Vitamin $\mathrm{D}_{2}$, also known as ergocalciferol, is produced predominantly by plants and fungi and forms part of the dietary intake of vitamin D. Vitamin $D_{3}$ is the endogenous form produced by humans. Biosynthesis begins with the photoisomerisation of 7-dehydrocholesterol (DHC) by ultraviolet $\mathrm{B}$ (UVB) radiation to form previtamin D in cutaneous tissue (Figure 1) [6]. Previtamin $\mathrm{D}$ then undergoes thermal-dependent isomerization to form vitamin $\mathrm{D}_{3}$ [cholecalciferol] [7]. The lipophilic cholecalciferol is biologically inactive and requires two sequential hydroxylations to reach its most active form. For this to occur, cholecalciferol preferentially binds to vitamin $\mathrm{D}$ binding protein (DBP) and is transported to the liver wherein hydroxylation of the 25-position carbon follows; the product of this reaction is 25-hydroxyvitamin $\mathrm{D}_{3}$ [calcidiol; $25(\mathrm{OH}) \mathrm{D}_{3}$ ]. It is this $25(\mathrm{OH}) \mathrm{D}_{3}$ form which is usually measured in serum to determine vitamin $\mathrm{D}$ levels in patients. An additional hydroxy group is added to the carbon at the 1 position through further hydroxylation which occurs primarily in the proximal tubule of the kidneys, but also in macrophages [8], osteoblasts [9], and osteoclasts [10] inter alia. The result is the most biologically active form of vitamin $\mathrm{D}, 1 \alpha, 25$ dihydroxyvitamin $\mathrm{D}_{3}$ [calcitriol; $1 \alpha, 25(\mathrm{OH})_{2} \mathrm{D}_{3}$ ]. Names and abbreviations of vitamin $\mathrm{D}_{3}$ are shown in Table 1 .

\section{Vitamin D Receptor}

The vitamin D receptor (VDR), through which $1 \alpha, 25(\mathrm{OH})_{2} \mathrm{D}_{3}$ acts, is a nuclear transcription factor which regulates gene expression in various cell types. Upon binding with vitamin $\mathrm{D}, \mathrm{VDR}$ forms a heterodimer with the retinoid $\mathrm{X}$ receptor (RXR). The resultant complex recognises and binds vitamin $\mathrm{D}$ response elements (VDREs) which consists of 2 hexameric motifs separated by a 3-base-pair spacer. Genomewide studies have identified between 2,000 and 8,000 VDREs depending on cell type [30, 31].

Due to its crucial role in vitamin D signalling, the VDR gene and its corresponding protein have been subject to much investigation in many diseases including osteoarthritis. In particular, genetic polymorphisms in the VDR gene and its surrounding regulatory sites, some of which can be located at large distances from the open reading frame, have been investigated using restriction fragment length polymorphism (RFLP). The technique employs restriction enzymes to cut DNA at specific sequence sites. The polymorphisms detected in the DNA, the fragments of which are analysed using gel electrophoresis and Southern blotting, include single nucleotide polymorphisms (SNPs) and insertion/deletion (INDEL) polymorphisms as they can alter the cleavage sites of the endoribonuclease and are therefore identifiable. In the $V D R$ gene, a number of polymorphisms have been identified and studied named EcoRV, Tru9I, FokI, BsmI, ApaI, and TaqI after the restriction enzymes used to identify them [32]. The latter four have been at the centre of investigations for possible involvement in OA. BsmI and ApaI are both located in intron 8, and TaqI is found in exon 9 [33]. These SNPs are considered synonymous due to the fact that they do not change the amino acid residue translated for in the final protein product. Conversely, FokI is considered nonsynonymous 
TABLE 1: Names and abbreviations of the forms of vitamin $\mathrm{D}_{3}$.

\begin{tabular}{lccc}
\hline Name & Alternative name & Abbreviation & \\
\hline Vitamin $\mathrm{D}_{3}$ & Cholecalciferol & - & Activity \\
$25-$ Hydroxyvitamin $\mathrm{D}_{3}$ & Calcidiol & $25(\mathrm{OH}) \mathrm{D}_{3}$ & Inactive \\
$1 \alpha, 25$-Dihydroxyvitamin $\mathrm{D}_{3}$ & Calcitriol & $1 \alpha, 25(\mathrm{OH})_{2} \mathrm{D}_{3}$ & Active \\
\hline
\end{tabular}

as the $\mathrm{T} / \mathrm{C}$ polymorphism ultimately changes the amino acid sequence and in doing so changes the start codon location meaning 2 protein forms of VDR exist, one of which is 3 amino acids longer than the other [32]. The reader is directed to a review by Uitterlinden et al. [32] for further details on these polymorphisms.

Despite the functional effects of these polymorphisms remaining elusive, four polymorphisms have been of particular interest in investigations in association studies with OA. It has been discovered that genetic polymorphisms may be associated with an increased susceptibility of symmetrical hand OA in Finnish females [34]. Additionally, a study in 1997 of postmenopausal women with knee OA found a possible association between a TaqI polymorphism and an increased risk of OA [35]. In 2009, Lee et al. [36] performed a meta-analysis of 10 studies (1,591 OA patients and 1,781 controls) into the association of the TaqI, BsmI, and ApaI polymorphisms with osteoarthritis. The studies analysed had investigated a range of the OA sites, including knee, lumbar spine, hand, and hip. Overall, it was found that there was no evidence to support an association between any of the SNPs and a susceptibility to OA; additionally, no association was found when studies were grouped into ethnicities (European or Asian). This conflicts with a more recent meta-analysis in which it was found that a small but statistically significant association exists between the ApaI polymorphism and the susceptibility to OA in Asian populations, an association not observed in Europeans [37]. This analysis included 9 of the previous 10 studies in addition to 3 new reports with a total of 2,104 OA patients and 2,939 controls. A possible association was discovered between the FokI polymorphism and OA, but the small number of studies limits the power of this analysis.

Whilst it appears that SNPs in the VDR gene show little if any association with knee OA in large groups, analysis of subgroups and ethnicities has shown possible links. Investigations into relationships between SNPs and different aspects of OA, for instance, joint space narrowing (JSN), osteophyte formation, or inflammation, will continue to be valuable. With the advent of next-generation sequencing, genomewide association studies (GWASs) offer a global genome perspective not attainable with the inherently biased candidate gene association studies. Two such studies performed on large scale population sizes failed to identify VDR gene polymorphisms to have a significant association with OA $[38,39]$. Moreover, a meta-analysis of 9 GWASs which included 5,636 knee OA patients and 16,972 controls showed no significant association between SNPs in the VDR gene and OA [40]. Combinations of SNPs from VDR and other OArelated genes, as opposed to assessing the involvements of a single polymorphism, may yield a more powerful insight into the genetic aspect of OA. However, the number of polymorphisms in the genome and the possible number of combinations present a challenge due to the sheer volume of data and the ability to analyze it.

\section{Vitamin D and Bone}

Contrary to historic opinion, osteoarthritis affects all tissues within the joint; the major tissue types include articular cartilage, subchondral bone, and the synovial membrane lining the diseased joint. Alterations in the physiological processes occurring in these tissues ultimately lead to the progression of OA. There are two main cell types in the subchondral bone which are of particular interest in OA: osteoblasts and osteoclasts. Changes in normal cellular activities cause aberrant bone remodeling, sclerosis, and osteophyte formation. Vitamin D is known to play a crucial role in the behaviour of metabolic processes in bone on which it has a range of effects in the pathophysiology of OA. A number of recent articles have reviewed the effects and roles of vitamin $\mathrm{D}$ in bone cells in detail [41-43]. Here, we look specifically at the changes in cellular behaviour in osteoarthritis (Figure 2).

4.1. Osteoblasts. Osteoblasts are single-nuclei cells derived from mesenchymal stem cells, a process which can be stimulated by $1 \alpha, 25(\mathrm{OH})_{2} \mathrm{D}_{3}[44]$ and whose primary functions are bone formation and mineralisation. Osteoblasts, particularly immature cells, express VDR $[45,46]$; this shows osteoblasts as key targets for vitamin D signalling. The phenotypic expressions of osteoblasts in OA are altered [47]. A study by Corrado et al. [48] found a number of interesting results when they investigated osteoblasts isolated from hip OA patients as well as healthy controls and osteoporosis patients. OA osteoblasts expressed a significantly lower receptor activator of nuclear factor- $\kappa$ B ligand (RANKL)/osteoprotegerin (OPG) ratio compared to healthy and osteoporotic cells and OPG expression in OA osteoblasts was significantly higher than controls and osteoporosis patients. Interestingly, these findings conflict with the results of Giner et al. [49] who found OPG secretions to be higher in osteoporotic osteoblasts compared to OA. RANKL and its decoy receptor OPG are regulators of osteoclastogenesis and thus bone resorption. Vitamin $\mathrm{D}$, specifically $1 \alpha, 25(\mathrm{OH})_{2} \mathrm{D}_{3}$, is known to stimulate osteoblastic bone mineralisation through the activation of nuclear VDR [44]. Proliferation of OA osteoblasts was significantly increased following vitamin $\mathrm{D}$ treatment compared to that of healthy osteoblasts [48]. Additionally, osteocalcin and alkaline phosphatase (two proteins involved in the formation and mineralisation of bone) production were both 


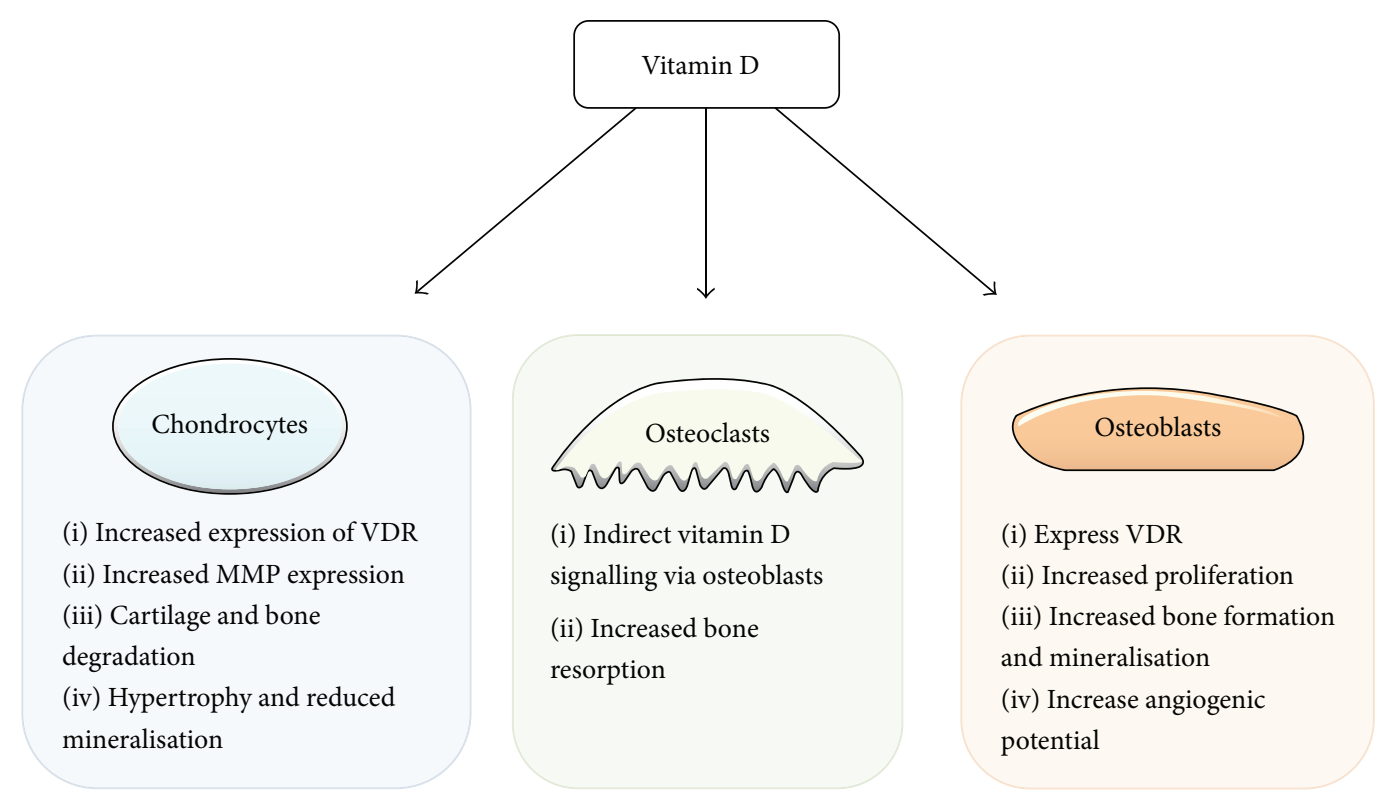

FIGURE 2: The effects of vitamin D on several different cell types in osteoarthritis including chondrocytes, osteoclasts, and osteoblasts. Vitamin $\mathrm{D}$ has a range of effects on cell types within osteoarthritis affected joints. Vitamin D acts through the vitamin D receptor and acts to alter gene expression which results in the phenotypic changes summarised here. Osteoclasts appear to respond indirectly to vitamin D signalling via osteoblasts and RANKL signalling. VDR: vitamin D receptor; MMP: matrix metalloproteinase.

significantly higher in OA osteoblasts compared to healthy and osteoporotic ones. The productions were significantly increased following vitamin D treatment [48]. This work supports Hilal and colleagues' investigation which found that $1 \alpha, 25(\mathrm{OH})_{2} \mathrm{D}_{3}$ induced a significantly higher production of osteocalcin in OA osteoblast-like cells compared to controls [47]. Taken together, these findings suggest that $\mathrm{OA}$ osteoblasts have increased vitamin $\mathrm{D}$-induced bone formation activity which could help to explain subchondral sclerosis and osteophyte formation, both of which are characteristics of advanced OA.

The Dickkopf (DKK) protein factor family is involved in the activation and inhibition of Wingless (Wnt) signalling induced bone formation through osteoblast proliferation and activity which in turn regulates bone remodeling $[48,50]$. DKK-1 expression was significantly lower in OA osteoblasts compared to healthy and osteoporotic cells; following vitamin D treatment, the expressions levels decreased significantly [48]. Conversely, DKK-2 expression was significantly higher in OA osteoblasts and was further increased with the addition of vitamin D [48]. These findings indicate the involvement of vitamin $\mathrm{D}$ in the cellular development of osteoblasts and support our own study in which significantly lower DKK-1 levels were found in plasma samples of OA patients compared with healthy controls [51].

An important aspect in the pathophysiology of OA is angiogenesis. The development and extension of vascular networks have been observed in the synovium, menisci, pannus, osteophytes, and osteochondral junction within affected OA joints [52]. Whilst an increase in blood supply to the tissues within an OA joint may be beneficial by supplying nutrients for cartilage repair, this growth is associated with the increase in pain through the extension of sensory nerves [53] and the loss of structural integrity of cartilage. Vascular endothelial growth factor (VEGF) is a potent angiogenic cytokine which plays an important role in OA. Our laboratory has shown both local and systemic levels to be associated with the severity of OA [54]. The expression of VEGF is regulated in part by $1 \alpha, 25(\mathrm{OH})_{2} \mathrm{D}_{3}$ in osteoarthritic osteoblasts [55]. Additionally, the angiogenic potential of the culture medium taken from OA osteoblasts was significantly increased following vitamin $\mathrm{D}$ treatment in vivo [55]. These observations support the idea that osteoblasts may regulate angiogenesis in subchondral bone and therefore may link vitamin D with the development and progression of OA.

4.2. Osteoclasts. Osteoclasts are large multinuclear cells with characteristic ruffled edges and sealing zones. Formed from the fusion of multiple preosteoclast cells, these specialised macrophages' primary function is the resorption of mineralised bone. This occurs in the resorption lacuna under acidic conditions by proteases such as cathepsin $\mathrm{K}$, matrix metalloproteinase- (MMP-) 9, and tartrate-resistant acid phosphatase. Whilst high doses of vitamin $\mathrm{D}$ have been shown to increase bone resorption $[56,57]$, there is limited evidence to suggest that vitamin D acts directly on osteoclasts due to the lack of VDR expression, though reports are conflicting and dependent on techniques used [45, 58-60]. However, vitamin $\mathrm{D}$ is thought to act indirectly through osteoblastic activity and the activation of the aforementioned RANKL signalling. 
TABLE 2: Common classifications of circulating vitamin D levels.

\begin{tabular}{lcc}
\hline Classification & \multicolumn{2}{c}{$25(\mathrm{OH}) \mathrm{D}$ concentration } \\
\hline Sufficient & $>20 \mathrm{ng} / \mathrm{mL}$ & $>49.92 \mathrm{nmol} / \mathrm{L}$ \\
Insufficient & $11-20 \mathrm{ng} / \mathrm{mL}$ & $27.46-49.92 \mathrm{nmol} / \mathrm{L}$ \\
Deficient & $<11 \mathrm{ng} / \mathrm{mL}$ & $<27.46 \mathrm{nmol} / \mathrm{L}$ \\
\hline
\end{tabular}

$25(\mathrm{OH}) \mathrm{D}_{3}=25$-hydroxyvitamin $\mathrm{D}_{3}$; to convert from $\mathrm{ng} / \mathrm{mL}$ to $\mathrm{nmol} / \mathrm{L}$, multiply by 2.496 .

4.3. Chondrocytes. Chondrocytes are the cell type responsible for the production and maintenance of the extracellular matrix (ECM) in cartilage. In OA, imbalances in the anabolic and catabolic processes result in the destruction and loss of articular cartilage ultimately leading to the progression of OA. Articular cartilage in the knee is typically avascular and receives nutrients and growth factors primarily from the synovial fluid. Additionally, chondrocytes exist in a relatively low cell density and as a result ECM production and repair is a slow process. Hypertrophic and proliferating chondrocytes express VDR $[45,46]$ and osteoarthritic chondrocytes more so than healthy cells $[61,62]$. Additionally, the presence of VDR expression is associated with MMP expression, specifically MMP-1, MMP-3, and MMP-9. MMPs enzymatically degrade bone and cartilage, which is disadvantageous in OA. Chondrocytes have been shown to directly regulate osteoclastogenesis through VDR signalling leading to the induction of RANKL expression [63]. Furthermore, $1 \alpha, 25(\mathrm{OH})_{2} \mathrm{D}_{3}$ and inorganic phosphate are involved in the hypertrophy and impaired mineralisation in osteoarthritic chondrocytes by activating extracellular-signal-regulated kinase (ERK)1/2 through FGF-23 signalling [62]. From these reports, it appears that vitamin $\mathrm{D}$ has negative effects on OA cartilage health. Future research should aim to investigate the extent and severity of these actions and their implications on the development and progression of OA.

\section{Vitamin D Deficiency and OA}

Vitamin D deficiency results in hypocalcemia and hypophosphatemia in addition to increase in PTH secretion. Hypovitaminosis D, generally (though not universally) defined as circulating serum $25(\mathrm{OH}) \mathrm{D}_{3}$ levels of $<20 \mathrm{ng} / \mathrm{mL}$ (Table 2 ), is prevalent worldwide [64] and frequently found to coexist with OA, particularly in the elderly patients. $24 \%$ of advanced stage elderly OA patients in a United Kingdom study were found to have deficient vitamin $\mathrm{D}$ levels according to the National Diet and Nutrition Survey definition of less than $40 \mathrm{nmol} / \mathrm{L}(\sim 16 \mathrm{ng} / \mathrm{mL})$ [65]. In a 2010 study in Ireland of rheumatology outpatients, $70 \%$ were found to be vitamin D deficient $(<21 \mathrm{ng} / \mathrm{mL})$ and $26 \%$ were severely deficient $(<12 \mathrm{ng} / \mathrm{mL})$ [66]. The study also noted $62 \%$ of OA patients suffered from hypovitaminosis D and $13 \%$ were severely affected. Additionally, low vitamin D levels have also been associated with radiographic hip OA [11].

It has been shown that the capacity of human skin to produce vitamin D decreases in old age [67]. Furthermore, vitamin D levels are associated with other known risk factors of OA including body mass index (BMI), age, very heavy manual labour, and exercise [68]. Research has been focused on investigating possible relationships between vitamin $\mathrm{D}$ levels and aspects of OA, as summarised in Table 3.

5.1. Development and Progression. Whether vitamin D deficiency increases the risk of developing $\mathrm{OA}$ remains to be answered. Conflicting results have been reported to date. A 22-year follow-up study of 805 Finns found that serum $25(\mathrm{OH}) \mathrm{D}_{3}$ levels were not associated with the incidence of either hip or knee OA [68]. This study supports an earlier report in which low vitamin $\mathrm{D}$ was found not to increase the risk of developing knee OA [12]. Furthermore, a large cohort study of 5,274 OA-free participants showed that low serum $25(\mathrm{OH}) \mathrm{D}_{3}$ levels were not associated with an increased risk of developing hip or knee OA over a 10 -year period [13]. However, contrary to these studies, lower serum vitamin $\mathrm{D}$ has been shown to be associated with OA. As part of the Osteoporosis Fractures in Men Study in the United States, an investigation found a high prevalence of vitamin $\mathrm{D}$ insufficiency or deficiency in hip OA patients and found that these patients were twice as likely to have hip OA [14]. In Egypt, research into newly diagnosed postmenopausal women found lower serum $25(\mathrm{OH}) \mathrm{D}_{3}$ was associated with knee OA when compared to healthy males [15]. Furthermore, an Iranian study observed a positive association between serum $25(\mathrm{OH}) \mathrm{D}_{3}$ and knee $\mathrm{OA}$ in patients under 60 years of age and noted a stronger association in younger participants [16]. Additionally, in patients with low BMD, low vitamin D status was found to be associated with an increased incidence of radiographic knee OA [17]. A systematic review performed by $\mathrm{Cao}$ et al. examined the associations between serum $25(\mathrm{OH}) \mathrm{D}_{3}$ and $\mathrm{OA}$ [69]. They found through analysing 15 studies that there exists strong evidence for an association between $25(\mathrm{OH}) \mathrm{D}_{3}$ and cartilage loss in knee joints; the authors also observed moderate evidence to support a positive association between low levels of vitamin $\mathrm{D}$ and radiographic knee OA. Low serum and low dietary vitamin $\mathrm{D}$ have been shown to be associated with the progression of knee OA [12, 17]. Moreover, as part of the Tasmanian Older Adult Cohort Study, Ding et al. found both vitamin D levels and sunlight exposure to be associated with decreased knee cartilage loss [18]. However, Felson et al. detailed two longitudinal studies with a total study population of 1,203 individuals. They found that there was no association between low vitamin $\mathrm{D}$ and structural worsening of affected joints (joint space narrowing by radiography and cartilage loss by magnetic resonance imaging) [19].

5.2. Pain and Function. Pain is a major symptom of OA, particularly in the knee. Pain is thought to be caused by a number of reasons including inflammation of the synovial membrane and the growth of sensory nerves through the subchondral bone into the articular cartilage [53]. Studies have shown conflicting results as to whether vitamin $\mathrm{D}$ is associated with pain in OA. In a 2-year randomised control study in which symptomatic knee OA patients were given oral doses of cholecalciferol to raise circulating levels to at least $36 \mathrm{ng} / \mathrm{mL}$ or a placebo, there was no reduction in the Western 


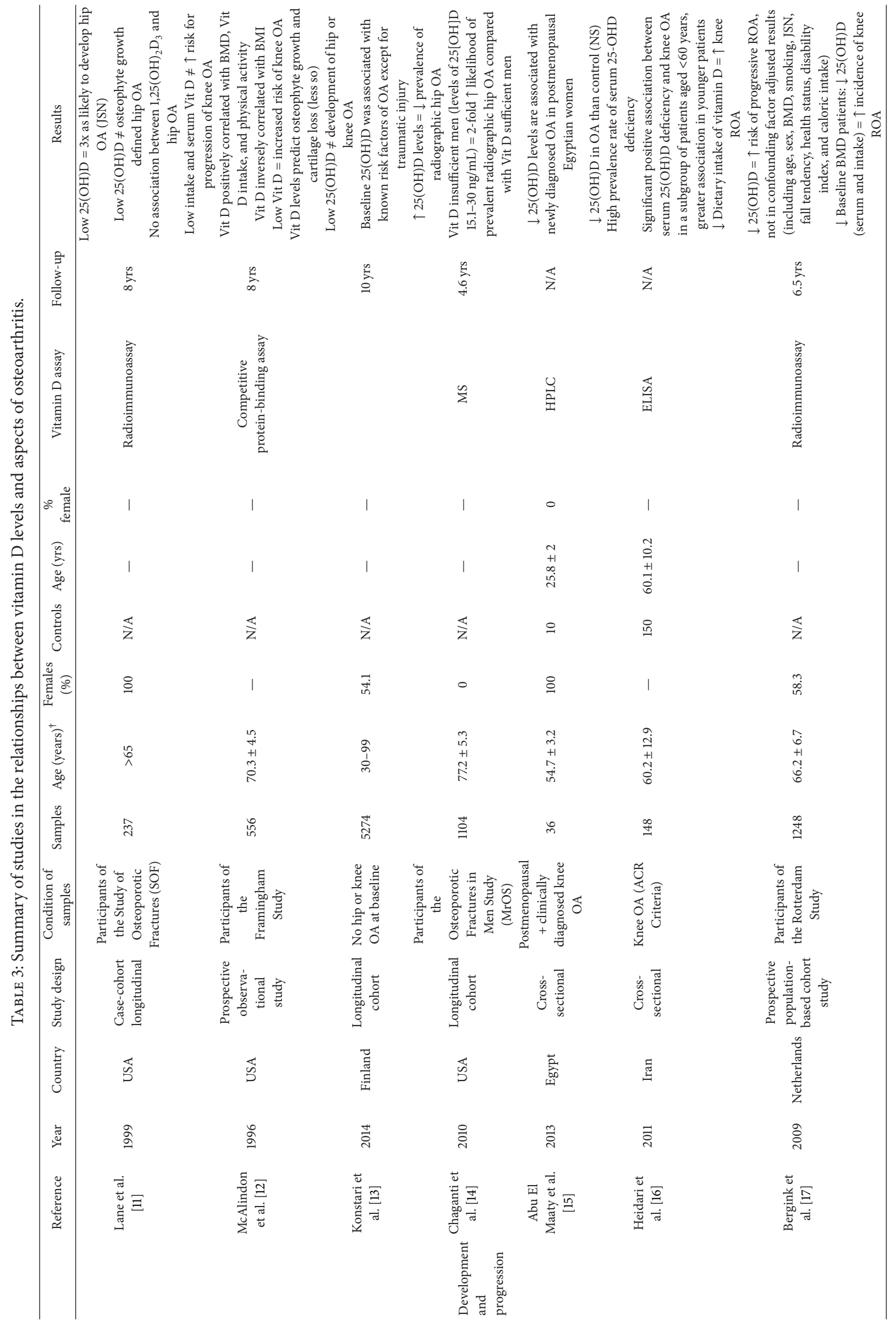




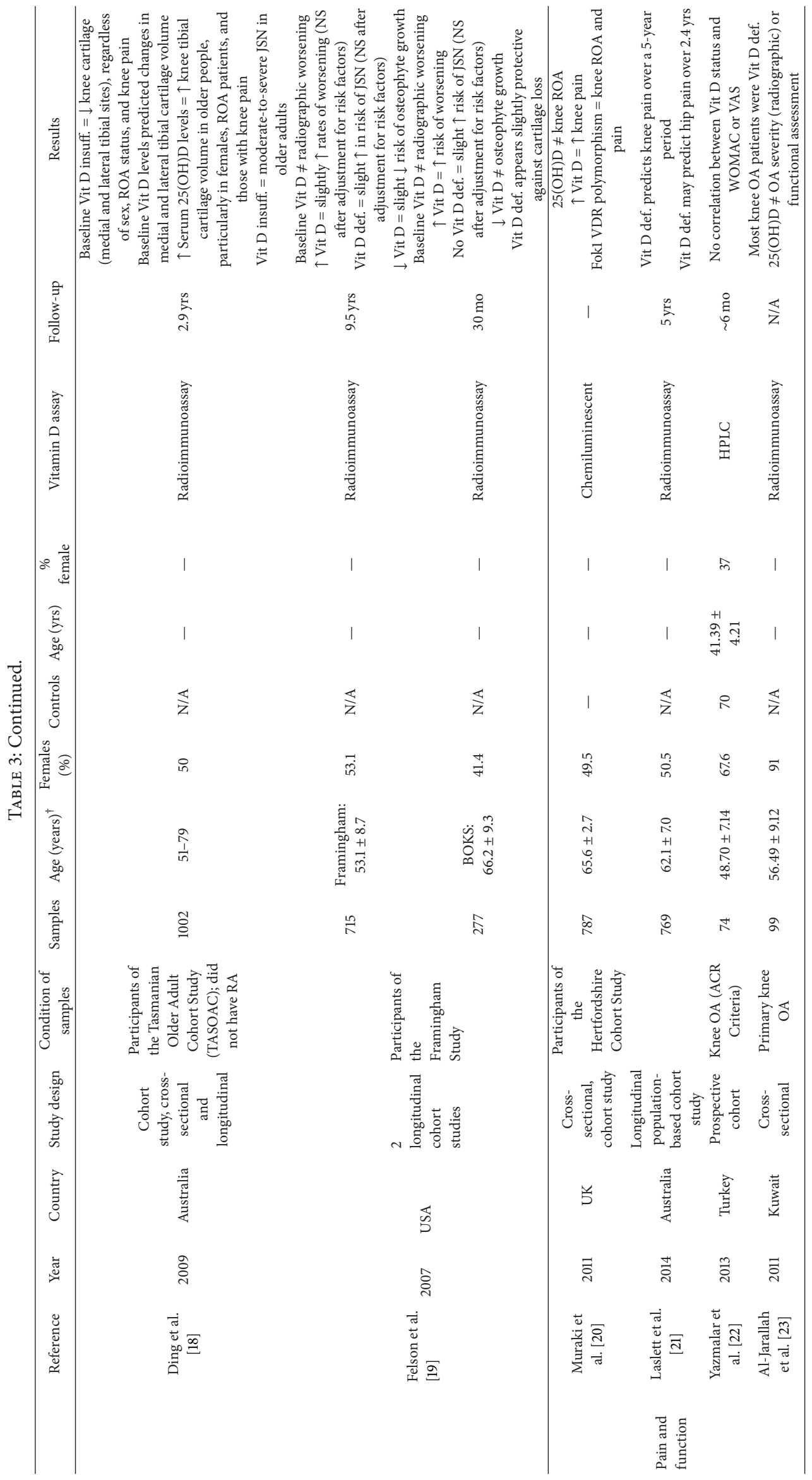




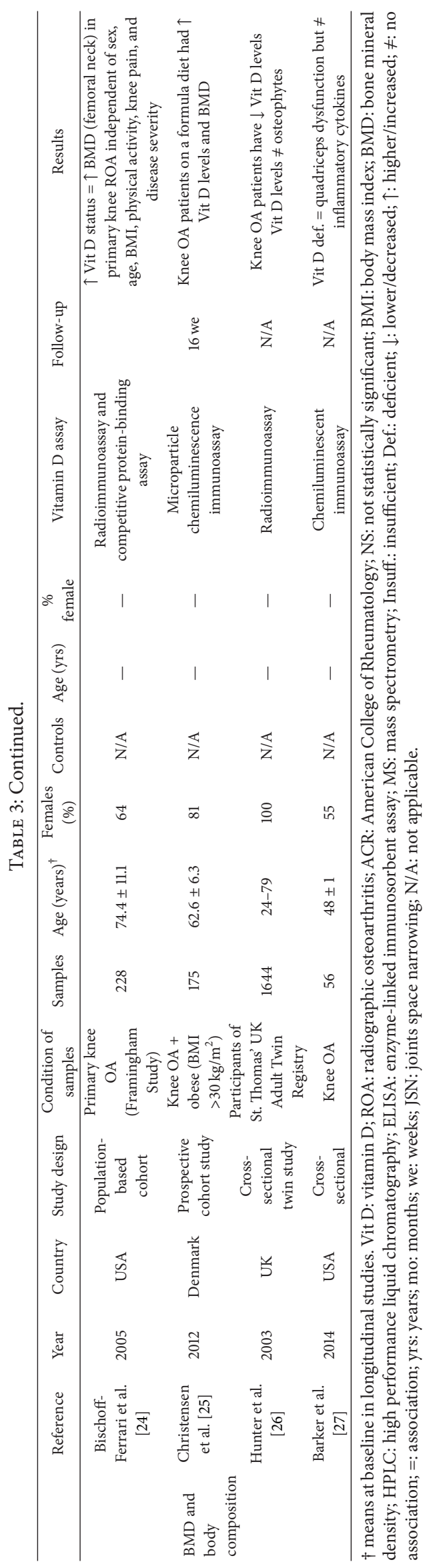


Ontario and McMaster Universities (WOMAC) knee pain scores or cartilage loss [29]. Additionally, 787 members of the Hertfordshire Cohort Study in the United Kingdom took part in a cross-sectional study that found no association between vitamin $\mathrm{D}$ levels and radiographic knee OA but did suggest a significant association between vitamin $\mathrm{D}$ and knee pain [20]. However, a longitudinal population-based cohort study of 769 participants found that moderate vitamin D deficiency (serum $25(\mathrm{OH}) \mathrm{D}_{3}=25 \mathrm{nmol} / \mathrm{L}$ ) was found to predict knee OA WOMAC pain scores over 5 years. Additionally, a similar trend was observed in hip pain scores, though this association did not reach statistical significance [21]. Furthermore, a double-blind parallel, placebo-controlled pilot trial of 103 knee OA patients found patients given vitamin $\mathrm{D}$ oral supplements (60,000 IU per day for 10 days followed by 60,000 IU once a month for 12 months) had slightly higher pain and functional scores compared to those receiving placebos after one-year follow-up [28]. However, seasonal vitamin D levels have been found not to be correlated with WOMAC scores in knee OA patients, nor did they associate with rheumatoid arthritis or ankylosing spondylitis disease activity [22].

Joint function is a useful indicator of $\mathrm{OA}$ as it reflects the socioeconomic effects of OA as well as the patients' quality of life. Vitamin D deficiency has been associated with preoperative Knee Society scores of functionality in OA patients undergoing arthroplasty surgery [65]. The same study found lower postoperative scores in vitamin $\mathrm{D}$ deficient patients than vitamin D sufficient patients though this did not reach statistical significance. A study of knee OA patients in Kuwait found that $93 \%$ were vitamin $\mathrm{D}$ deficient; however, neither $\mathrm{X}$-ray grading nor functionality was associated with hypovitaminosis D [23]. Vitamin D levels have been shown to predict the outcomes of OA patients undergoing total hip replacement. A positive correlation exists between both preoperative and postoperative Harris hip scores and plasma $25(\mathrm{OH}) \mathrm{D}_{3}$ levels [70]. The research presented to date is conflicting as to the effects low vitamin D levels have on the functional aspects of knee OA.

5.3. Bone Mineral Density. Bone mineral density (BMD) has also been investigated due to the crucial involvement vitamin $\mathrm{D}$ has in bone metabolism. A study of 228 primary knee OA patients found that there was a significant positive association between the BMD of the femoral neck and serum $25(\mathrm{OH}) \mathrm{D}_{3}$ which was independent of age, sex, BMI, knee pain, level of physical activity, and disease severity [24]. Moreover, a 2year longitudinal study containing 1,122 males, as part of a population-based study in Australia, found that low serum $25(\mathrm{OH}) \mathrm{D}_{3}$ put men at increased risk of low BMD [71]. Bone mineral density was seen to increase following a 16-week weight loss program in which 175 obese knee OA patients received formula products which were enriched with vitamin D. Vitamin D levels rose significantly during the study as PTH levels decreased [25]. Further, a study of 56 hip OA patients who had undergone primary total hip arthroplasty found that BMD loss was prevented in the lumbar spine by vitamin $\mathrm{D}$ analogues alfacalcidol $\left(1 \alpha(\mathrm{OH}) \mathrm{D}_{3}\right)$ and alendronate compared with no-treatment controls [72]. However,
Breijawi et al. discovered no association or correlation between serum vitamin D levels and BMD of either lumbar spine or proximal femur sites, though they did note a high prevalence of hypovitaminosis D in their hip and knee OA patients [73]. Moreover, in a twin study of 1,644 females, vitamin $\mathrm{D}$ levels were not lower in OA patients after adjusting for BMI and age nor were there any significant associations with changes to subchondral bone or bone remodelling [26]. Despite some conflicting results, there appears to be an association between low circulating vitamin D and low BMD in OA patients. A decrease in $\mathrm{BMD}$ is associated with progressive cartilage loss in knee OA $[74,75]$ and so reflects a wide view of the disease in different tissues. Osteoblast activity is increased in OA and so it would be expected that higher BMD would follow. However, BMD is usually measured in the lumbar spine or femoral neck, sights often not associated with $\mathrm{OA}$ in the patients under investigations. Sclerosis of subchondral bone occurring in affected joint is characteristic of OA. It could be hypothesised that the effects of vitamin $\mathrm{D}$ are felt differently in different tissues. Studies investigating localised expression of VDR and the resultant effects of vitamin D signalling are needed.

The results of the studies thus far bespeak an unclear depiction of the associations vitamin $\mathrm{D}$ has with OA. Whilst there appears to be substantial evidence for low vitamin D levels being connected with the incidence of OA and low $\mathrm{BMD}$, these results are not without their controversy. There currently exists insufficient evidence to draw reasonable conclusions with respect to pain and functional changes depending on circulating vitamin $\mathrm{D}$ concentrations. The controversial results presented herein may owe their differences to a number of factors. Different techniques and laboratory procedures have varying degrees of accuracy in determining vitamin D levels. Study populations in different geographical locations as well as different ethnic backgrounds could also explain their opposing conclusions. Hypovitaminosis D research could be further hindered by the fact that the limit at which circulating $25(\mathrm{OH}) \mathrm{D}_{3}$ concentrations become deficient has yet to be universally defined. Research has attempted to make such a definition using a range of techniques and it appears at least $50 \mathrm{nmol} / \mathrm{L}(\sim 20 \mathrm{ng} / \mathrm{mL})$ of serum $25(\mathrm{OH}) \mathrm{D}_{3}$ is necessary to normalise PTH levels and for optimal bone cell function ([76] and the references therein). Nonetheless, assessing a range of serum levels will aid in the determination of low or varying levels of vitamin $\mathrm{D}$ and their association with OA. To fully determine the relationship between vitamin $\mathrm{D}$, as well as hypovitaminosis $\mathrm{D}$, and the development and progression of OA, large scale longitudinal studies conducted at multiple centres at different geographical latitudes and climates, along with including individuals with various skin pigmentations and of different ethnicities, are required. In conjunction with further studies, large scale meta-analyses will yield more powerful interpretations of the existing findings and help to elucidate any associations low vitamin $\mathrm{D}$ has with $\mathrm{OA}$.

5.4. Body Composition. BMI is a strong risk factor associated with $\mathrm{OA}$ and particularly knee $\mathrm{OA}$ where a $5 \mathrm{~kg} / \mathrm{m}^{2}$ increase 


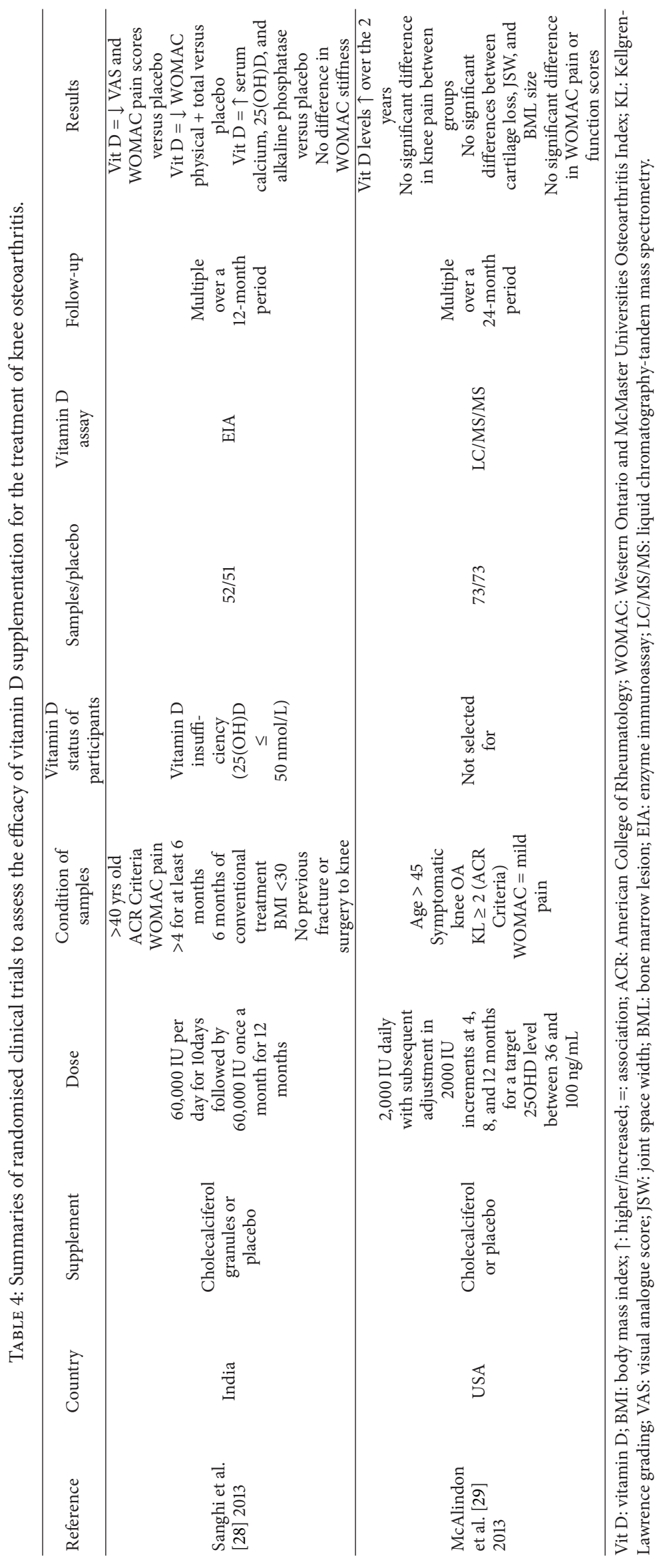


in BMI is associated with a $35 \%$ increase in the risk of knee OA [77]. Vitamin D signalling has been observed to play important roles in adipose tissue [78]. Moreover, inverse correlations between vitamin D concentrations and BMI as well as waist circumference and regional adiposity have been observed in a range of individuals [79-81]. Interestingly, a study of 48 bariatric females undergoing gastric bypass surgery which found that obese patients have lower serum vitamin D levels than controls also suggested that the low vitamin $\mathrm{D}$ in OA patients was the consequence of less sun exposure rather than as a result of OA [82]. Muscle strength has been reported to play an important role in knee OA [83] as quadriceps weakness is associated with increased joint space narrowing $[84,85]$. Vitamin D deficiency is associated with decreased quadriceps strength in knee OA patients [27]. However, higher thigh muscle mass does not appear to imply protection against the development or progression of knee OA [86]. From this, it is important to consider the effects of low vitamin $\mathrm{D}$ and body composition in knee OA. When performing and interpreting meta-analysis in the future, caution should be taken to consider the relationship vitamin $\mathrm{D}$ has with BMI, muscle strength, and muscle mass and the collective effects on the disease.

\section{Increasing Vitamin D Levels in Patients}

Whilst further research is required to fully understand the role of vitamin $\mathrm{D}$ in $\mathrm{OA}$, it is apparent that vitamin $\mathrm{D}$ deficiency may play a role in the pathogenesis of osteoarthritis on a clinical level. However, these effects are not mirrored at the cellular level where results indicate vitamin $\mathrm{D}$ has detrimental effects on joint tissues. The reason behind these conflictions has yet to be elucidated and a paucity of large scale clinical trials exists to test the long-term effects of vitamin D supplementation on knee OA [28, 29]. Table 4 summarises these trials which are not without controversy and opinions remain divided as to the benefits of vitamin D supplementation. Whilst there are some overlaps, the trials hitherto are in different populations with differing overall baseline vitamin $\mathrm{D}$ statuses and different dosage strategies and follow-up periods. This makes drawing conclusions difficult and limited. Moreover, vitamin D appears to be implemented more so with structural changes within OA affected joints, such as cartilage loss, rather than symptomatic aspects of the disease, for instance, pain, function, and stiffness [69]. However, the clinicaltrials.gov website currently lists a number of trials which are ongoing that aim to shed light on the safety and efficacy of vitamin D supplementation in $\mathrm{OA}$ and possible benefits against the disease development and progression. Additionally, little work has been completed to determine the optimal dose of supplement for maximum effect with minimal negative effects. Consequently, it would be premature to pass judgment on the use of such treatment methods in the context of knee OA. Instead, more research into the mechanisms in which vitamin D deficiency is linked to disease development and progression, as well as its use as a preventative or mitigating treatment, would be useful.

\section{Concluding Remarks}

Vitamin D plays a crucial role in bone metabolism. It has a range of effects on various cell types within joints which have been shown to be altered on osteoarthritis. Subchondral bone sclerosis is a hallmark of OA, but so too is bone remodeling which is associated with loss of bone density, increased porosity, and transient bone loss, a paradox explored by Burr and Gallant [87]. It could be postulated that vitamin D, with its conflicting actions on bone growth, may be involved in the changes in bone behaviours at different stages of OA progression. Further studies are required to settle the debate as to the role of vitamin D deficiency in the development and progression of OA. Moreover, the relationships between low vitamin $\mathrm{D}$ levels and pain and joint function have yet to be fully elucidated.

\section{Conflict of Interests}

The authors declare that there is no conflict of interests regarding the publication of this paper.

\section{Acknowledgments}

This work was supported by the Higher Education Research Promotion and National Research University Project of Thailand, Office of the Higher Education Commission through the Aging Society Cluster (WCU-58-037-AS), Chulalongkorn University.

\section{References}

[1] V. L. Johnson and D. J. Hunter, "The epidemiology of osteoarthritis," Best Practice \& Research Clinical Rheumatology, vol. 28, pp. 5-15, 2014.

[2] J. H. Kellgren and J. S. Lawrence, "Radiological assessment of osteo-arthrosis," Annals of the Rheumatic Diseases, vol. 16, no. 4, pp. 494-502, 1957.

[3] P. H. Anderson, A. G. Turner, and H. A. Morris, "Vitamin D actions to regulate calcium and skeletal homeostasis," Clinical Biochemistry, vol. 45, no. 12, pp. 880-886, 2012.

[4] S. Liu, W. Tang, J. Zhou et al., "Fibroblast growth factor 23 is a counter-regulatory phosphaturic hormone for vitamin D," Journal of the American Society of Nephrology, vol. 17, no. 5, pp. 13051315, 2006.

[5] D. Aslan, M. D. Andersen, L. B. Gede et al., "Mechanisms for the bone anabolic effect of parathyroid hormone treatment in humans," Scandinavian Journal of Clinical and Laboratory Investigation, vol. 72, no. 1, pp. 14-22, 2012.

[6] J. A. MacLaughlin, R. R. Anderson, and M. F. Holick, "Spectral character of sunlight modulates photosynthesis of previtamin D3 and its photoisomers in human skin," Science, vol. 216, no. 4549, pp. 1001-1003, 1982.

[7] S. Battault, S. J. Whiting, S. L. Peltier, S. Sadrin, G. Gerber, and J. M. Maixent, "Vitamin D metabolism, functions and needs: from science to health claims," European Journal of Nutrition, vol. 52, no. 2, pp. 429-441, 2013.

[8] H. Reichel, H. P. Koeffler, and A. W. Norman, "Synthesis in vitro of 1,25-dihydroxyvitamin D3 and 24,25-dihydroxyvitamin D3 by interferon- $\gamma$-stimulated normal human bone marrow and 
alveolar macrophages," The Journal of Biological Chemistry, vol. 262, no. 23, pp. 10931-10937, 1987.

[9] M. van Driel, M. Koedam, C. J. Buurman et al., "Evidence for auto/paracrine actions of vitamin D in bone: 1alpha-hydroxylase expression and activity in human bone cells," The FASEB Journal, vol. 20, no. 13, pp. 2417-2419, 2006.

[10] M. Kogawa, P. H. Anderson, D. M. Findlay, H. A. Morris, and G. J. Atkins, "The metabolism of $25-(\mathrm{OH})$ vitamin $\mathrm{D}_{3}$ by osteoclasts and their precursors regulates the differentiation of osteoclasts," The Journal of Steroid Biochemistry and Molecular Biology, vol. 121, no. 1-2, pp. 277-280, 2010.

[11] N. E. Lane, L. R. Gore, S. R. Cummings et al., "Serum vitamin D levels and incident changes of radiographic hip osteoarthritis: a longitudinal study. Study of osteoporotic fractures research group," Arthritis and Rheumatism, vol. 42, no. 5, pp. 854-860, 1999.

[12] T. E. McAlindon, D. T. Felson, Y. Zhang et al., "Relation of dietary intake and serum levels of vitamin d to progression of osteoarthritis of the knee among participants in the framingham study," Annals of Internal Medicine, vol. 125, no. 5, pp. 353-359, 1996.

[13] S. Konstari, L. Kaila-Kangas, T. Jaaskelainen et al., "Serum 25hydroxyvitamin D and the risk of knee and hip osteoarthritis leading to hospitalization: a cohort study of 5274 Finns," Rheumatology, vol. 53, no. 10, pp. 1778-1782, 2014.

[14] R. K. Chaganti, N. Parimi, P. Cawthon, T. L. Dam, M. C. Nevitt, and N. E. Lane, "Association of 25-hydroxyvitamin D with prevalent osteoarthritis of the hip in elderly men: the osteoporotic fractures in men study," Arthritis \& Rheumatism, vol. 62, no. 2, pp. 511-514, 2010.

[15] M. A. Abu El Maaty, R. S. Hanafi, S. E. Badawy, and M. Z. Gad, "Association of suboptimal 25-hydroxyvitamin D levels with knee osteoarthritis incidence in post-menopausal Egyptian women," Rheumatology International, vol. 33, no. 11, pp. 29032907, 2013.

[16] B. Heidari, P. Heidari, and K. Hajian-Tilaki, "Association between serum vitamin D deficiency and knee osteoarthritis," International Orthopaedics, vol. 35, no. 11, pp. 1627-1631, 2011.

[17] A. P. Bergink, A. G. Uitterlinden, J. P. T. M. van Leeuwen et al., "Vitamin D status, bone mineral density, and the development of radiographic osteoarthritis of the knee: the rotterdam study," Journal of Clinical Rheumatology, vol. 15, no. 5, pp. 230-237, 2009.

[18] C. Ding, F. Cicuttini, V. Parameswaran, J. Burgess, S. Quinn, and G. Jones, "Serum levels of vitamin D, sunlight exposure, and knee cartilage loss in older adults: the Tasmanian older adult cohort study," Arthritis and Rheumatism, vol. 60, no. 5, pp. 13811389, 2009.

[19] D. T. Felson, J. Niu, M. Clancy et al., "Low levels of vitamin D and worsening of knee osteoarthritis: results of two longitudinal studies," Arthritis \& Rheumatism, vol. 56, no. 1, pp. 129-136, 2007.

[20] S. Muraki, E. Dennison, K. Jameson et al., "Association of vitamin D status with knee pain and radiographic knee osteoarthritis," Osteoarthritis and Cartilage, vol. 19, no. 11, pp. 1301-1306, 2011.

[21] L. L. Laslett, S. Quinn, J. R. Burgess et al., "Moderate vitamin d deficiency is associated with changes in knee and hip pain in older adults: a 5-year longitudinal study," Annals of the Rheumatic Diseases, vol. 73, no. 4, pp. 697-703, 2014.

[22] L. Yazmalar, L. Ediz, M. Alpayci, O. Hiz, M. Toprak, and I. Tekeoglu, "Seasonal disease activity and serum vitamin D levels in rheumatoid arthritis, ankylosing spondylitis and osteoarthritis," African Health Sciences, vol. 13, no. 1, pp. 47-55, 2013.

[23] K. F. Al-Jarallah, D. Shehab, A. Al-Awadhi, I. Nahar, M. Z. Haider, and M. A. Moussa, "Are 25(OH)D levels related to the severity of knee osteoarthritis and function?" Medical Principles and Practice, vol. 21, no. 1, pp. 74-78, 2011.

[24] H. A. Bischoff-Ferrari, Y. Zhang, D. P. Kiel, and D. T. Felson, "Positive association between serum 25-hydroxyvitamin D level and bone density in osteoarthritis," Arthritis Care \& Research, vol. 53, no. 6, pp. 821-826, 2005.

[25] P. Christensen, E. M. Bartels, B. F. Riecke et al., "Improved nutritional status and bone health after diet-induced weight loss in sedentary osteoarthritis patients: a prospective cohort study," European Journal of Clinical Nutrition, vol. 66, no. 4, pp. 504509, 2012.

[26] D. J. Hunter, D. Hart, H. Snieder, P. Bettica, R. Swaminathan, and T. D. Spector, "Evidence of altered bone turnover, vitamin $\mathrm{D}$ and calcium regulation with knee osteoarthritis in female twins," Rheumatology, vol. 42, no. 11, pp. 1311-1316, 2003.

[27] T. Barker, V. T. Henriksen, V. E. Rogers et al., "Vitamin D deficiency associates with $\gamma$-tocopherol and quadriceps weakness but not inflammatory cytokines in subjects with knee osteoarthritis," Redox Biology, vol. 2, no. 1, pp. 466-474, 2014.

[28] D. Sanghi, A. Mishra, A. C. Sharma et al., "Does vitamin D improve osteoarthritis of the knee: a randomized controlled pilot trial," Clinical Orthopaedics and Related Research, vol. 471, no. 11, pp. 3556-3562, 2013.

[29] T. McAlindon, M. LaValley, E. Schneider et al., "Effect of vitamin D supplementation on progression of knee pain and cartilage volume loss in patients with symptomatic osteoarthritis: a randomized controlled trial," The Journal of the American Medical Association, vol. 309, no. 2, pp. 155-162, 2013.

[30] D. Goltzman, G. N. Hendy, and J. H. White, "Vitamin D and its receptor during late development," Biochimica et Biophysica Acta-Gene Regulatory Mechanisms, vol.1849, no. 2, pp. 171-180, 2015.

[31] J. W. Pike and M. B. Meyer, "Fundamentals of vitamin d hormone-regulated gene expression," The Journal of Steroid Biochemistry and Molecular Biology, vol. 144, pp. 5-11, 2014.

[32] A. G. Uitterlinden, Y. Fang, J. B. J. Van Meurs, H. A. P. Pols, and J. P. T. M. Van Leeuwen, "Genetics and biology of vitamin D receptor polymorphisms," Gene, vol. 338, no. 2, pp. 143-156, 2004.

[33] A. G. Uitterlinden, Y. Fang, A. P. Bergink, J. B. J. Van Meurs, H. P. T. M. Van Leeuwen, and H. A. P. Pols, "The role of vitamin D receptor gene polymorphisms in bone biology," Molecular and Cellular Endocrinology, vol. 197, no. 1-2, pp. 15-21, 2002.

[34] S. Solovieva, A. Hirvonen, P. Siivola et al., "Vitamin D receptor gene polymorphisms and susceptibility of hand osteoarthritis in Finnish women," Arthritis Research \& Therapy, vol. 8, article R20, 2006.

[35] R. W. Keen, D. J. Hart, J. S. Lanchbury, and T. D. Spector, "Association of early, osteoarthritis of the knee with a Taq I polymorphism of the vitamin D receptor gene," Arthritis and Rheumatism, vol. 40, no. 8, pp. 1444-1449, 1997.

[36] Y. H. Lee, J. H. Woo, S. J. Choi, J. D. Ji, and G. G. Song, "Vitamin d receptor taqi, BsmI and ApaI polymorphisms and osteoarthritis susceptibility: a meta-analysis," Joint Bone Spine, vol. 76, no. 2, pp. 156-161, 2009.

[37] Z.-H. Zhu, X.-Z. Jin, W. Zhang et al., "Associations between vitamin $\mathrm{D}$ receptor gene polymorphisms and osteoarthritis: an 
updated meta-analysis," Rheumatology, vol. 53, no. 6, Article ID ket418, pp. 998-1008, 2014.

[38] H. J. M. Kerkhof, R. J. Lories, I. Meulenbelt et al., "A genomewide association study identifies an osteoarthritis susceptibility locus on chromosome 7q22," Arthritis \& Rheumatism, vol. 62, no. 2, pp. 499-510, 2010.

[39] E. Zeggini, K. Panoutsopoulou, L. Southam et al., "Identification of new susceptibility loci for osteoarthritis (arcogen): a genomewide association study," The Lancet, vol. 380, pp. 815-823, 2012.

[40] C. Rodriguez-Fontenla, M. Calaza, E. Evangelou et al., "Assessment of osteoarthritis candidate genes in a meta-analysis of nine genome-wide association studies," Arthritis and Rheumatology, vol. 66, no. 4, pp. 940-949, 2014.

[41] M. van Driel and J. P. van Leeuwen, "Vitamin D endocrine system and osteoblasts," BoneKEy Reports, vol. 3, article 493, 2014.

[42] B. Lanske, M. J. Densmore, and R. G. Erben, "Vitamin D endocrine system and osteocytes," BoneKEy Reports, vol. 3, article 494, 2014.

[43] N. Takahashi, N. Udagawa, and T. Suda, "Vitamin D endocrine system and osteoclasts," Bonekey Reports, vol. 3, article 495, 2014.

[44] M. van Driel, M. Koedam, C. J. Buurman et al., "Evidence that both $1 \alpha, 25$-dihydroxyvitamin $\mathrm{D}_{3}$ and 24-hydroxylated $\mathrm{D}_{3}$ enhance human osteoblast differentiation and mineralization," Journal of Cellular Biochemistry, vol. 99, no. 3, pp. 922-935, 2006.

[45] Y. Wang, J. Zhu, and H. F. Deluca, "Identification of the vitamin $D$ receptor in osteoblasts and chondrocytes but not osteoclasts in mouse bone," Journal of Bone and Mineral Research, vol. 29, no. 3, pp. 685-692, 2014.

[46] J. A. Johnson, J. P. Grande, P. C. Roche, and R. Kumar, "Ontogeny of the 1,25-dihydroxyvitamin D3 receptor in fetal rat bone," Journal of Bone and Mineral Research, vol. 11, no. 1, pp. 56-61, 1996.

[47] G. Hilal, J. Martel-Pelletier, J.-P. Pelletier, P. Ranger, and D. Lajeunesse, "Osteoblast-like cells from human subchondral osteoarthritic bone demonstrate an altered phenotype in vitro: possible role in subchondral bone sclerosis," Arthritis and Rheumatism, vol. 41, no. 5, pp. 891-899, 1998.

[48] A. Corrado, A. Neve, A. Macchiarola, A. Gaudio, A. Marucci, and F. P. Cantatore, "RANKL/OPG ratio and DKK-1 expression in primary osteoblastic cultures from osteoarthritic and osteoporotic subjects," The Journal of Rheumatology, vol. 40, no. 5, pp. 684-694, 2013.

[49] M. Giner, M. J. Rios, M. J. Montoya, M. A. Vázquez, L. Naji, and R. Pérez-Cano, "RANKL/OPG in primary cultures of osteoblasts from post-menopausal women. Differences between osteoporotic hip fractures and osteoarthritis," Journal of Steroid Biochemistry and Molecular Biology, vol. 113, no. 1-2, pp. 46-51, 2009.

[50] R. Baron and G. Rawadi, "Minireview: targeting the Wnt/betacatenin pathway to regulate bone formation in the adult skeleton," Endocrinology, vol. 148, no. 6, pp. 2635-2643, 2007.

[51] S. Honsawek, A. Tanavalee, P. Yuktanandana, S. Ngarmukos, N. Saetan, and S. Tantavisut, "Dickkopf-1 (Dkk-1) in plasma and synovial fluid is inversely correlated with radiographic severity of knee osteoarthritis patients," BMC Musculoskeletal Disorders, vol. 11, article 257, 2010.

[52] P. I. Mapp and D. A. Walsh, "Mechanisms and targets of angiogenesis and nerve growth in osteoarthritis," Nature Reviews Rheumatology, vol. 8, no. 7, pp. 390-398, 2012.
[53] D. A. Walsh, D. F. Mcwilliams, M. J. Turley et al., "Angiogenesis and nerve growth factor at the osteochondral junction in rheumatoid arthritis and osteoarthritis," Rheumatology, vol. 49, no. 10, pp. 1852-1861, 2010.

[54] N. Saetan, S. Honsawek, A. Tanavalee et al., "Relationship of plasma and synovial fluid vascular endothelial growth factor with radiographic severity in primary knee osteoarthritis," International Orthopaedics, vol. 38, no. 5, pp. 1099-1104, 2014.

[55] A. Neve, F. P. Cantatore, A. Corrado, A. Gaudio, S. Ruggieri, and D. Ribatti, "In vitro and in vivo angiogenic activity of osteoarthritic and osteoporotic osteoblasts is modulated by VEGF and vitamin D3 treatment," Regulatory Peptides, vol. 184, pp. 8184, 2013.

[56] M. Rossini, D. Gatti, O. Viapiana et al., "Short-term effects on bone turnover markers of a single high dose of oral vitamin $\mathrm{D}_{3}$," Journal of Clinical Endocrinology and Metabolism, vol. 97, no. 4, pp. E622-E626, 2012.

[57] M. Rossini, S. Adami, O. Viapiana et al., "Dose-dependent short-term effects of single high doses of oral vitamin D3 on bone turnover markers," Calcified Tissue International, vol. 91, no. 6, pp. 365-369, 2012.

[58] C. Menaa, J. Barsony, S. V. Reddy, J. Cornish, T. Cundy, and G. D. Roodman, "1,25-dihydroxyvitamin D3 hypersensitivity of osteoclast precursors from patients with Paget's disease," Journal of Bone and Mineral Research, vol. 15, no. 2, pp. 228-236, 2000.

[59] A. P. Mee, J. A. Hoyland, I. P. Braidman, A. J. Freemont, M. Davies, and E. B. Mawer, "Demonstration of vitamin D receptor transcripts in actively resorbing osteoclasts in bone sections," Bone, vol. 18, no. 4, pp. 295-299, 1996.

[60] J. Merke, G. Klaus, U. Hugel, R. Waldherr, and E. Ritz, "No 1,25-dihydroxyvitamin D3 receptors on osteoclasts of calciumdeficient chicken despite demonstrable receptors on circulating monocytes," The Journal of Clinical Investigation, vol. 77, no. 1, pp. 312-314, 1986.

[61] L. C. Tetlow and D. E. Woolley, "Expression of vitamin D receptors and matrix metalloproteinases in osteoarthritic cartilage and human articular chondrocytes in vitro," Osteoarthritis and Cartilage, vol. 9, no. 5, pp. 423-431, 2001.

[62] T. Orfanidou, K. N. Malizos, S. Varitimidis, and A. Tsezou, "1,25-Dihydroxyvitamin $\mathrm{D}_{3}$ and extracellular inorganic phosphate activate mitogen-activated protein kinase pathway through fibroblast growth factor 23 contributing to hypertrophy and mineralization in osteoarthritic chondrocytes," Experimental Biology and Medicine, vol. 237, no. 3, pp. 241-253, 2012.

[63] R. Masuyama, I. Stockmans, S. Torrekens et al., "Vitamin D receptor in chondrocytes promotes osteoclastogenesis and regulates FGF23 production in osteoblasts," The Journal of Clinical Investigation, vol. 116, no. 12, pp. 3150-3159, 2006.

[64] A. Mithal, D. A. Wahl, J.-P. Bonjour et al., "Global vitamin D status and determinants of hypovitaminosis D," Osteoporosis International, vol. 20, no. 11, pp. 1807-1820, 2009.

[65] J. A. Jansen and F. S. Haddad, "High prevalence of vitamin D deficiency in elderly patients with advanced osteoarthritis scheduled for total knee replacement associated with poorer preoperative functional state," Annals of the Royal College of Surgeons of England, vol. 95, no. 8, pp. 569-572, 2013.

[66] M. Haroon, U. Bond, N. Quillinan, M. J. Phelan, and M. J. Regan, "The prevalence of vitamin D deficiency in consecutive new patients seen over a 6-month period in general rheumatology clinics," Clinical Rheumatology, vol. 30, no. 6, pp. 789-794, 2011. 
[67] J. MacLaughlin and M. F. Holick, "Aging decreases the capacity of human skin to produce vitamin D3," The Journal of Clinical Investigation, vol. 76, no. 4, pp. 1536-1538, 1985.

[68] S. Konstari, M. Paananen, M. Heliövaara et al., "Association of 25-hydroxyvitamin D with the incidence of knee and hip osteoarthritis: a 22-year follow-up study," Scandinavian Journal of Rheumatology, vol. 41, no. 2, pp. 124-131, 2012.

[69] Y. Cao, T. Winzenberg, K. Nguo, J. Lin, G. Jones, and C. Ding, "Association between serum levels of 25-hydroxyvitamin D and osteoarthritis: a systematic review," Rheumatology, vol. 52, no. 7, pp. 1323-1334, 2013.

[70] D. H. Nawabi, K. F. Chin, R. W. Keen, and F. S. Haddad, "Vitamin $\mathrm{D}$ deficiency in patients with osteoarthritis undergoing total hip replacement: a cause for concern?" The Journal of Bone \& Joint Surgery-British Volume, vol. 92, no. 4, pp. 496-499, 2010.

[71] K. Bleicher, R. G. Cumming, V. Naganathan et al., "Predictors of the rate of BMD loss in older men: findings from the CHAMP study," Osteoporosis International, vol. 24, no. 7, pp. 1951-1963, 2013.

[72] N. Iwamoto, Y. Inaba, N. Kobayashi, T. Ishida, Y. Yukizawa, and T. Saito, "A comparison of the effects of alendronate and alfacalcidol on bone mineral density around the femoral implant and in the lumbar spine after total hip arthroplasty," The Journal of Bone \& Joint Surgery-American Volume, vol. 93, no. 13, pp. 1203-1209, 2011.

[73] N. Breijawi, A. Eckardt, M. B. Pitton et al., "Bone mineral density and vitamin $\mathrm{d}$ status in female and male patients with osteoarthritis of the knee or hip," European Surgical Research, vol. 42, no. 1, pp. 1-10, 2008.

[74] J. Y. Lee, W. F. Harvey, L. L. Price, J. K. Paulus, B. DawsonHughes, and T. E. McAlindon, "Relationship of bone mineral density to progression of knee osteoarthritis," Arthritis and Rheumatism, vol. 65, no. 6, pp. 1541-1546, 2013.

[75] Y. Zhang, M. T. Hannan, C. E. Chaisson et al., "Bone mineral density and risk of incident and progressive radiographic knee osteoarthritis in women: the Framingham Study," Journal of Rheumatology, vol. 27, no. 4, pp. 1032-1037, 2000.

[76] P. R. Ebeling, "Vitamin D and bone health: epidemiologic studies," BoneKEy Reports, vol. 3, article 511, 2014.

[77] L. Jiang, W. Tian, Y. Wang et al., "Body mass index and susceptibility to knee osteoarthritis: a systematic review and metaanalysis," Joint Bone Spine, vol. 79, no. 3, pp. 291-297, 2012.

[78] C. Ding, D. Gao, J. Wilding, P. Trayhurn, and C. Bing, "Vitamin D signalling in adipose tissue," British Journal of Nutrition, vol. 108, no. 11, pp. 1915-1923, 2012.

[79] E. Fish, G. Beverstein, D. Olson, S. Reinhardt, M. Garren, and J. Gould, "Vitamin D status of morbidly obese bariatric surgery patients," Journal of Surgical Research, vol. 164, no. 2, pp. 198202, 2010.

[80] P. G. Vashi, C. A. Lammersfeld, D. P. Braun, and D. Gupta, "Serum 25-hydroxyvitamin D is inversely associated with body mass index in cancer," Nutrition Journal, vol. 10, article 51, 2011.

[81] S. Cheng, J. M. Massaro, C. S. Fox et al., "Adiposity, cardiometabolic risk, and vitamin D status: the framingham heart study," Diabetes, vol. 59, no. 1, pp. 242-248, 2010.

[82] E. Grethen, R. McClintock, C. E. Gupta et al., "Vitamin D and hyperparathyroidism in obesity," Journal of Clinical Endocrinology and Metabolism, vol. 96, no. 5, pp. 1320-1326, 2011.

[83] B. Øiestad, C. Juhl, I. Eitzen, and J. Thorlund, "Knee extensor muscle weakness is a risk factor for development of knee osteoarthritis. A systematic review and meta-analysis," Osteoarthritis and Cartilage, vol. 23, no. 2, pp. 171-177, 2015.

[84] N. A. Segal, N. A. Glass, J. Torner et al., "Quadriceps weakness predicts risk for knee joint space narrowing in women in the MOST cohort," Osteoarthritis and Cartilage, vol. 18, no. 6, pp. 769-775, 2010.

[85] N. A. Glass, J. C. Torner, L. A. F. Law et al., “The relationship between quadriceps muscle weakness and worsening of knee pain in the most cohort: a 5-year longitudinal study," Osteoarthritis and Cartilage, vol. 21, no. 9, pp. 1154-1159, 2013.

[86] N. A. Segal, C. Findlay, K. Wang, J. C. Torner, and M. C. Nevitt, "The longitudinal relationship between thigh muscle mass and the development of knee osteoarthritis," Osteoarthritis and Cartilage, vol. 20, no. 12, pp. 1534-1540, 2012.

[87] D. B. Burr and M. A. Gallant, "Bone remodelling in osteoarthritis," Nature Reviews Rheumatology, vol. 8, no. 11, pp. 665-673, 2012. 


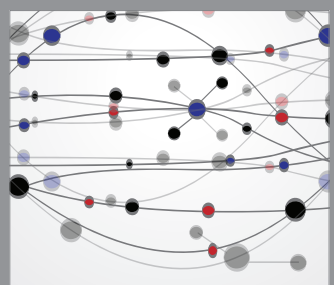

The Scientific World Journal
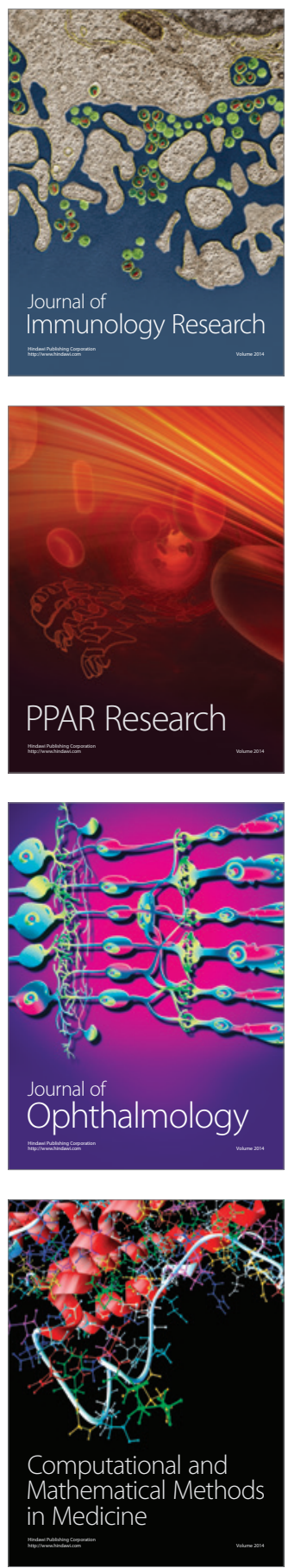

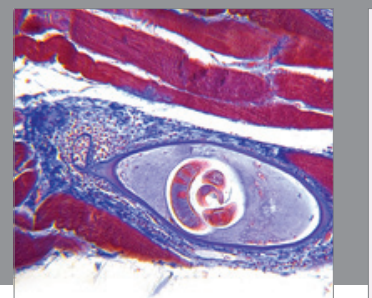

Gastroenterology

Research and Practice
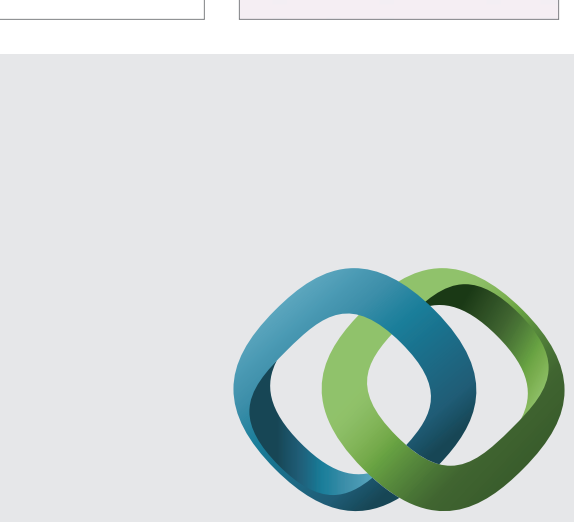

\section{Hindawi}

Submit your manuscripts at

http://www.hindawi.com
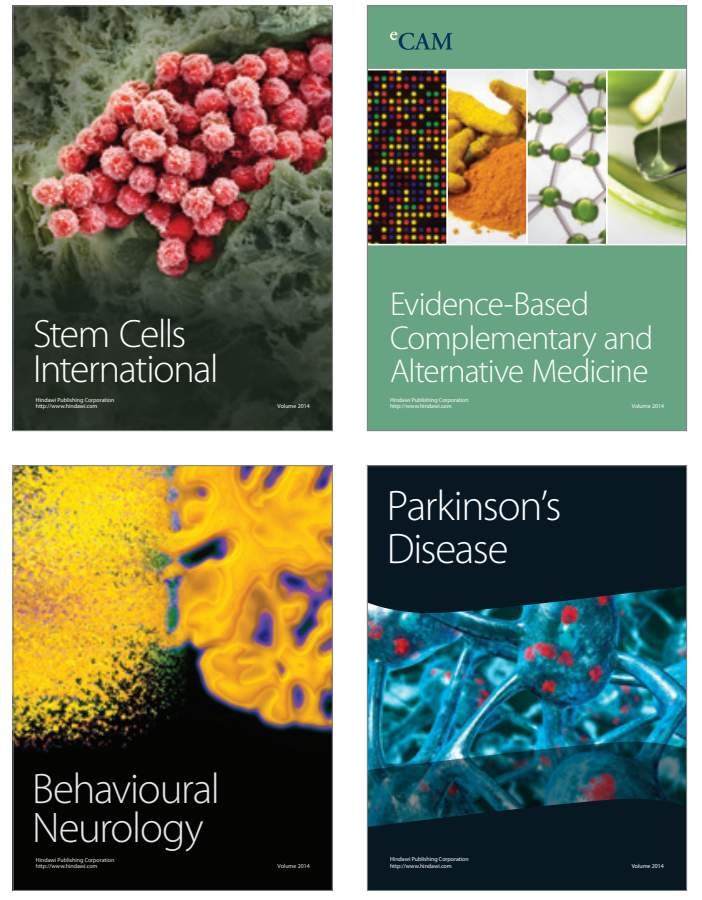
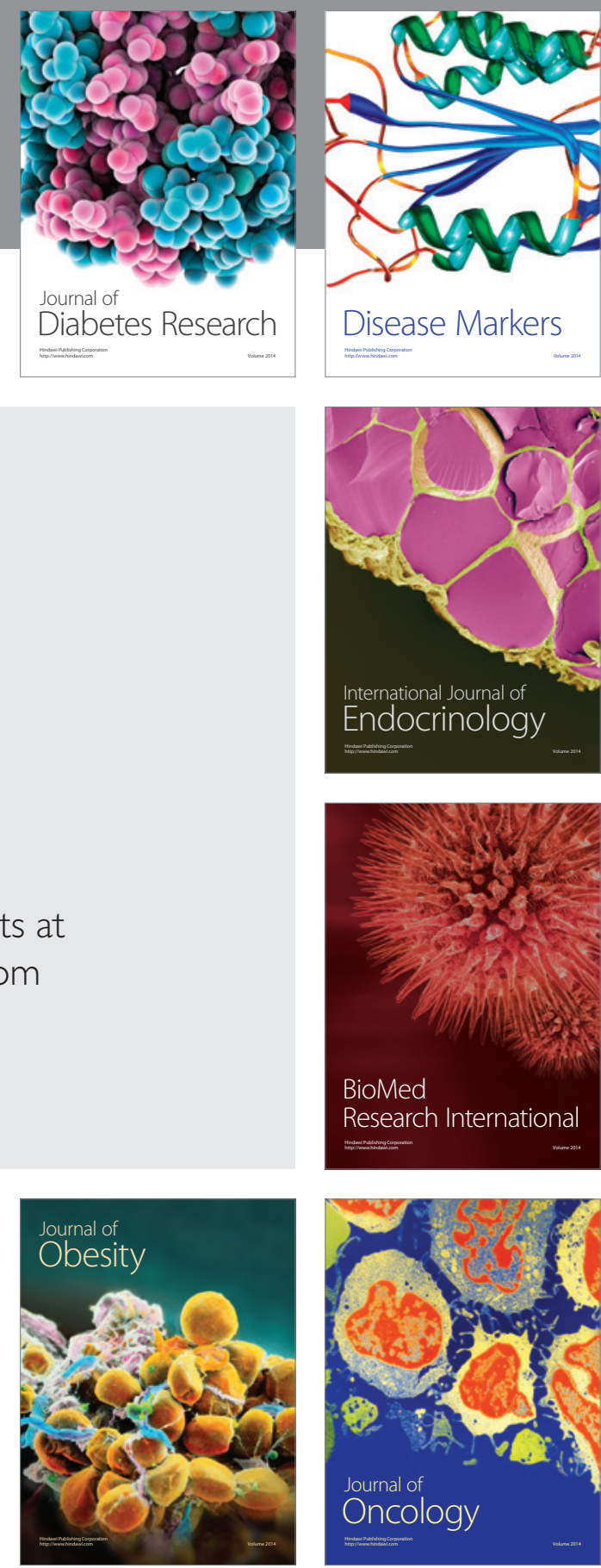

Disease Markers
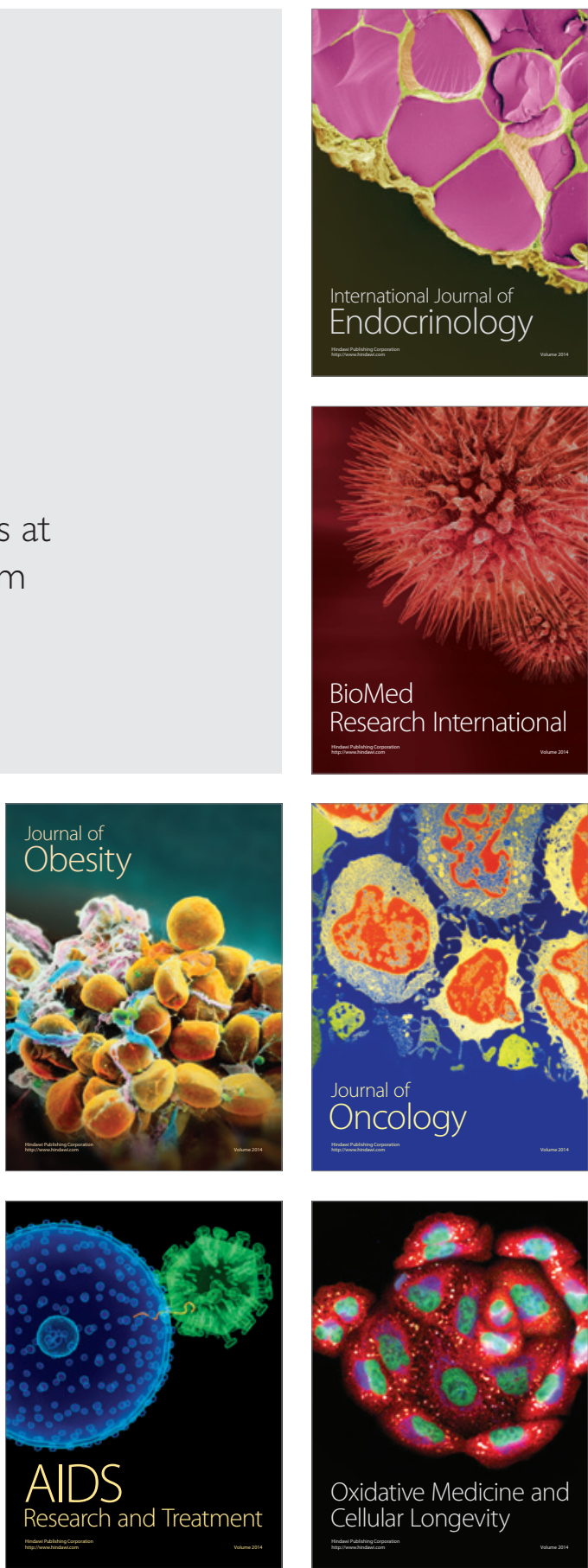